\title{
THE INTRODUCTION OF AN HOLISTIC DESIGN APPROACH THROUGH A TEACHING COMPANY SCHEME
}

\author{
${ }^{*}$ R.H Middleton, *M.D Saxon, ${ }^{\dagger} G$ Phillips, ${ }^{+} M$ Frost, ${ }^{*} B . J$ Griffiths, ${ }^{*} D$ Rees, and ${ }^{*}$ Esat
}

*Brunel University, UK, ${ }^{\dagger}$ TMD Ltd., UK.

Traditional design approaches separate the various functions of design such as material selection, performance modelling and tolerance specification into discrete entities. Whilst this allows more focused methods to be used at each stage, areas of conflict or benefit may be overlooked, and the designer is left to bring the loose ends together. This paper looks at a synthesis approach that draws upon a number of current design themes. The design process is considered along with various aspects such as product development, Design For ' $\mathrm{X}$ ' methodologies and material selection. The need for the preservation of design knowledge and reasoning, the so called wh-? questions, within the process are considered along with various models of the design process. The paper draws these various aspects together to form a more holistic approach to design. The application of this technique within the Teaching Company Scheme is briefly discussed.

\section{INTRODUCTION}

\section{The Design Process}

Design is a creative process. It seems to be one of the few human activities that seeks to integrate disciplines rather than compartmentalise them. A designer needs to understand a wide range of fields, including general engineering, materials technology, manufacturing technology, human psychology, aesthetics, art, science to name but a few. The degree to which all these come into play will obviously depend upon the field the designer is working in. There is still a tendency to divide the design process into fragmented blocks, executed in strict order. There is some sense to this, as it enables people to focus on the area where their skills are most applicable, and the flow of the process becomes more ordered and manageable. The problems occur when things are taken too literally. Important elements of the process may not be fully linked, it is very hard to say "We will be creative and conceptual now" and then "We will now be algorithmic in our approach."

The design process is in many respects a structured and technical "suck-it-and-see" method. The current trend is towards the use of design or development teams, with the various activities in design being allowed to overlap. This is known as Concurrent Engineering, and this will be discussed in Current Methods.

\section{The Teaching Company Scheme (TCS)}

TMD Ltd. is one of the world leaders in the manufacturing and development of high-power microwave amplifiers and associated subsystems for RADAR, communications, ESM (Electronic Support Measures) and ELINT (ELectronic INTeligence) applications. The company supports a wide product range of switched power supplies, magnetron, klystrons, travelling wave tubes to specialist subsystems. The company has established an international reputation over fifty years for high performance, reliability and quality. TMD is committed to the continuing development of microwave technology.

With this strategic aim in mind, the TCS formed with Brunel University aims to refine several of the company's existing products to reduce cost and complexity, and hence provide low cost, high quality products for TMD's current and future customers. To support this objective, the Scheme aims to improve and develop design tools (such as modelling and simulation) and design methods (such as Design For Assembly, Design For Manufacture). This had been documented in Saxon et al [1].

\section{Microwave Devices}

Microwaves have been in use since the early 1940 's when the Allied and Axis powers engaged in the first 'battle of the airwaves.' Since that time the range of uses to which microwaves has been put to has increased dramatically. Microwaves use now extends to industrial heating; drying, curing, materials processing, domestic cooking and communications. Unlike much of the amplifier technology developed in the 1940 and 1950 (i.e. Valve systems) which have been replaced by semiconductor devices of one sort or another, most microwave amplifiers are still vacuum devices. This does not imply that microwave amplification technology is stuck in the past. Solid state devices have only established 
themselves in the low-power, low- to midfrequency range, Staprans, [2]. High power, high frequency applications are the sole domain of vacuum devices Granatstein et al [3]. For more information on microwave technology, particularly klystrons, see Smith et al [4]. Details of the design methods used can be found in Middleton et al. [5].

\section{TRADITIONAL DESIGN}

\section{Evolutionary and Adaptive Design}

The concept of evolutionary design is loosely based on the theory of natural selection. In this scheme 'good' designs survive and adapt to the demands of the market place, while 'bad' designs die out. There are two problems with this. Designs can take a long time to evolve. Also, there is no measure of why a design has succeeded, the only measure of success is it's continued survival, in essence it is a tautology.

It is rare for designs to truly evolve into a completely different design. Mountain bikes are a development of the normal bicycle, but they are still bicycles. Adaptive design would be a better label for this kind of design, where a product adapts over time to suit it's environment. There are a number of products that can change a great deal, but still essentially rely on the same concepts. The bicycle and motorcar are two such examples. The overall structure of these products is essentially unchanged, mostly because it does not need to change.

Selection pressures should be fatal. Selection should take place on whether the presence or absence of a feature is a disadvantage. By failing to follow evolutionary theory correctly, the lack of fatal selection pressures leads to the risk of increasing product entropy. It is clear from the many documented successes in the application of Design for ' $X$ ' methods (Boothroyd, [6]) that many products are more complicated than they need to be to perform their fundamental function.

\section{"Over-The-Wall" Design}

This is the 'traditional' way things were, and often still are, done. A product is designed, an attempt is then made to manufacture it, which may result in redesign, the customer then uses it, and further redesign may be carried out. Communication between the shop floor, designers, and end-users is limited. The drawbacks of this approach can be summarised into two points:

- Designs are not questioned by engineers or shop floor technicians at an early stage, so manufacturing problems are not realised until late in development, or even during production.

- Once a design has been 'proven' functionally, it is unlikely to change, and any subsequent problems are tolerated.

\section{CURRENT METHODS}

\section{Concurrent Engineering}

Concurrent Engineering aims to overcome the deficiencies of 'Over-The-Wall' design. This differs from Simultaneous Engineering in that concurrence implies co-operation between different activities, and not simply an overlap in the time plan (Lindberg [7]). This approach has advantages, as it allows those with an influence on the design to be involved at a relatively early stage, with a view to preventing late changes, and promoting greater economy in design. Much of the success of Lockheed's Skunk Works development plant came from the direct access the shop floor and development group had to each other (Rich, [8]).

The most effective way to overcome the barriers associated with function based company structures is to form cross-functional product development teams at an early stage Saxon et al [9]. Teamworking avoids the typical situation where a whole range of problems are thrown up at a late design review [7]. However, the formation of dedicated teams may not be the most efficient use of manpower. This is especially true in small to medium sized companies, where there are insufficient resources to cover dedicated development, production and support teams. In such cases, a matrix structure is more appropriate, where people report to both a project manager and a functional manager. This structure allows flexibility, and allows the company to cope with the conflict between product development and production needs (Handy, [10]) , but to work without conflict, responsibilities must be defined carefully.

Product development teams may include:

- designers and engineers, to provide detailed technical knowledge of product function and manufacturing capability.

- production operators or technicians. Feedback from those who are at the front end of manufacture is essential, and may suggest improvements based on current products. Barton [11] confirms that the enforcement of design rules without feedback from manufacturing can result in significant problems being overlooked.

- marketing and sales, to ensure that the product under development will meet customer requirements. 
Methods, such as Boothroyd-Dewhurst DFMA (Design For Manufacturing and Assembly), can be applied to aid the consultative stages associated with the design process.

\section{Design For ' $\mathrm{X}$ ' Methods}

Tools such as DFA (Design For Assembly), and DFM (Design For Manufacture) are collectively known as DFX tools. Such tools are designed to encourage analysis and optimisation of designs. This usually involves the systematic breakdown of an existing product, analysing each component with respect to function, assembly or manufacturing difficulty etc. to obtain a quantitative and objective rating of the product. The idea is then to target components or subassemblies with a low score, and redesign or eliminate them.

These methods often generate great improvements, but take time to introduce due to the education required, and the time required to build up the product information database. The analysis may be implemented as an iterative process, perhaps targeting a key product or assembly stage to start with, then perhaps moving on to other subassemblies based on the results achieved.

As part of this analysis process, a considerable amount of information must be collected about the product in order to rate the design. The collection process encourages discussion, and generates alternative designs which can also be rated using the system. The kinds of information required for these types of analysis are not always found on drawings or procedure sheets, and in established products we need to delve deeper into why historical design decisions have been made. In general the DFX tools are designed with mechanical features in mind. Either specialist add-ons, or great care, is required when applying these methods to 'unusual' products.

\section{Algorithmic Approach}

Recently, work has been carried out on introducing a more algorithmic approach to design, mainly by Russian and German researchers. One thrust has focused on the use of design catalogues, these are collections of known and proven solutions to design problems (Pahl and Beitz, [12]). These catalogues cover physical and working principles, standard parts, materials and so on. The aim is to assist the designer in focusing on correct solutions to problems quickly whilst allowing for the designers creative input.
The other thrust has been in the use of computer based algorithms. By breaking the design process into a series of small steps, the possibility of producing an algorithmic solution to each one increases. This allows the design process to be automated and has much in common with computer based scientific discovery (ValdesPerez, [13]). Details on the more algorithmic approach to design can be found in Altshuller [14] and a summary of this method is given by Barnard [15]. A commercial system, called the "The Invention Machine ${ }^{\mathrm{TM},}$ (Tsourikov, [16]), has been developed from these ideas. The advantages and disadvantages of computer based design are discussed in Middleton, et al [17].

\section{MISSING LINKS}

\section{Dealing With The Wh-? Information}

The wh-? questions, where, when why, what and how, are all questions that will, or should, be asked and recorded during the design process. The most important of these from a historical point of view is WHY. This is often obvious during the design phase, but years later, considerable effort may be required to recover information, causing work to be repeated. If the original designers are not around then the information is lost. This is rather like having the recipe to make a loaf of bread, the cook knows the bread has to stand in a warm place, but not why. If bread is needed quickly, there is a chance that this process could be omitted if the reason for the procedure is not known.

Traditionally, documented information available for a given product design will include a drawing pack, and a set of procedures defining the manufacturing process for the product. This does not provide designers with the 'experience' information on why important material and process decisions were made. Lenau [18] describes this lack of material and process information as the "missing element in Design For Manufacture". Unless it is know why decisions are made, there will be an inherent resistance to changing proven designs. One must bear in mind that future designers may need to refer back to designs, or research documentation, produced some years earlier. In the field of microwave devices, the basic design principles have remained relatively unchanged for thirty years.

Design for ' $X$ ' methods need to be applied with care when analysing existing designs. If the 'why' information is incomplete, parts which perform a function may be eliminated or merged. This could lead to unusual operation of the product, or the return of a problem which was fixed by the eliminated part. 
An example is given by (Lindermann, [19]). A cost reduction programme resulted in the removal of a feature from a pressed component. Removing the feature caused problems in service, and a design team was formed. Several weeks later, their solution was presented - replacement of the original feature. Methods for capturing and associating the wh-? information with engineering drawings within a commercially available CAD system are under development [19]). Alternative methods are also discussed in [17].

\section{Optimising Production}

It is generally accepted that when using DFA and DFM on existing products, DFA is applied first. This is because DFA takes a view of the product as a whole and the relationship between components and generally involves combining or eliminating parts, thus affecting the mechanical design. On the other hand, DFM considers the manufacture and function of the individual components in turn. DFM may also involve some compromises in terms of the assembly efficiency of the design, for example breaking down a complex component to improve its manufacturability.

\section{Putting The Design Into Computer Aided Design}

Producing engineering drawings on a computer is now commonplace, but Computer Aided Drafting is not Computer Aided Design. Computer Aided Design uses systems with the ability to generate and manipulate three- dimensional representations of parts and assemblies, and can link to simulation software to test the design. Computer Aided Drafting uses only the basics of the tool kit, and is a mere wireframe outline of the design process.

Simulation needs to be carried out carefully, and users need to be aware of the limitations of the packages involved so that they can be alert to anomalous results (Smith, [20]) and use other codes to check their findings if necessary (Symonds and $\mathrm{Yu},[21]$ ).

Work is underway to produce methods to model the design process to include factors such as life-cycle analysis. This work, as well progress on modelling the entire design process, is reviewed by Krause Krause et al [22].

\section{Life Cycles}

In recent years the consideration of a products 'cradle-to-grave' life cycle has become more important. Design for the environment has been emphasised through legislation, for example the recent introduction of a tax on waste dumping at landfill sites.

As well as being easy to manufacture and assemble, products may also need to be tested and maintained throughout their life. Attention should be paid to such issues during the design process. Design for DISassembly may be important. One manufacturer used a snap fit case for a range of expensive portable communication radios, only to find that when repairs were required due to general wear and tear, the cases could not be opened without damage.

The life cycle of the product may also influence the materials used during manufacture.

\section{Material and Process Selection}

The selection of the correct material is very important. The selection methods employed need to ensure that the optimum materials are selected for the design. A big temptation is to stick to what one knows will work. In cases where the reliability of the product is important, new materials and processes will need to be proved before they area accepted. One example of this is non-recoverable space probes. The range of materials and joining/cutting methods is steadily expanding, it would be very difficult for a designer to keep up to date with all the developments and their implications. Choices may be limited due to reluctance to move outside the 'comfort zones' of the designer or the company. Some changes are market led, for example the increasing use of injection mouldings in the styled casings of consumer products. Proving new materials and processes is often expensive and time consuming.

The materials and processes available to the designer can have a great influence on the cost of a design in terms of production, and wider life cycle considerations.

\section{HOLISTIC APPROACH}

In the TMD-Brunel TCS, Teaching Company two Associates act as the project managers for the design and modelling aspects of the scheme respectively. Each Associate co-ordinates half of the development project, and seeks input from those with the required expertise as appropriate Unfortunately, this approach does not always uncover all possible solutions during the design or development process.

People who seem functionally removed from a particular subject have a different outlook. They can introduce new contacts, and may provide the most unexpected and inventive ideas. To cover 
this, input is invited from a variety of people when generating ideas, and alternatives are circulated for feedback. Brainstorming meetings are one solution, but these can result in only the person with the most powerful voice (in terms of volume or status) being heard, so one-to-one discussions are also valuable.

The design project within this TCS has resulted in the successful application of DFA and DFM methods to a product (the Travelling-Wave Tube) that would not normally be considered due to its low volume production, although the degree of complexity within the product has enabled profitable analysis to be carried out [1]. The following benefits have been realised:

- $40 \%$ Part count reduction, with the associated benefits of reduced inventory costs, inspection costs, reduced documentation requirements etc...

- $50 \%$ reduction in the number of assembly and processing operations, with corresponding cost and time savings.

- Reduced manufacturing cost by the elimination of a brazing stage and a precision machining stage.

There have also been qualitative benefits including:

- the documentation of the assembly process, by the construction of a document, providing a single reference source for all the information required to design and manufacture the product.

- the redesign project has resulted in a great deal of discussion and communication around the design decisions taken. Comments, ideas, and feedback not normally available in traditional documentation have also been included in the above document.

- justification of DFA analysis software, accessible to the Scheme and the university. This will enable more comprehensive analysis, and will also be used to develop undergraduate projects and case studies at the university.

To support the design and development processes within TMD, the other half of the scheme aims to upgrade and document existing electron-optics modelling software to allow development engineers quicker and easier access.

Therefore, we can conclude that this TCS has resulted in the transfer of new techniques to TMD, with both quantitative and qualitative improvements to design activities.

\section{CONCLUSIONS}

This paper has looked at various aspects of the design process and has discussed how they have been brought together in a Teaching Company Scheme. Some parts of the approach to design have been implemented other are under development.

Design is a wide ranging activity, whilst focusing on one individual element can lead to great benefits [6], the design activity as a whole must be considered not only from a technical/ manufacturing stance bur also from a human and historical viewpoint.

\section{ACKNOWLEDGEMENTS}

The authors would like to thank Thorn Microwave Devices for permission to publish. Messrs R.H. Middleton and M.D. Saxon are funded by the UK Engineering and Physical Science Research Council and the Department of Trade and Industry. via the Teaching Company Scheme in conjunction with Brunel University and Thorn Microwave Devices.

\section{REFERENCES}

1. Saxon, M.D. and Griffiths, B.J., 1996," The Applicability of the Boothroyd Dewhurst Design For Assembly Methodology to Low Volume Manufacture", Advances in Manufacturing X Proceedings of the 12th NCMR.

2. Staprans, A., 1989, "Evolution of Microwave Power Sources", Microwave Systems News, 19, No. 6 , pp. 20-29.

3. Granatstein, V.L., and Alexeff, I., 1987, "High Power Microwave Sources", Artech House, London, UK.

4. Smith, M.J., and Phillips, G., 1995, "Power Klystrons Today", Research Studies Press, Taunton UK.

5. Middleton, R.H., Saxon, M., Phillips, G., Rees, D., and Esat, I. (1996) Trends in Electron Gun Design, Proceedings of the $3^{\text {rd }}$ ASME-ESDA conference, Montpellier, France.

6. Boothroyd, G., 1994, "Product Design For Manufacture and Assembly," Computer-Aided Design, 26, No. 7, pp. 505-520

7. Lindberg, L. (1993) "Notes on Concurrent Engineering", Annals of the CIRP, 42, No. 1., pp. 159-162

8. Rich, B., (1995) "Skunk Works", Warner Press, London

9. Saxon, M, Griffiths, B. and Frost, M, (1996) "The Introduction of Design For Assembly Techniques through a Teaching : Company 
Scheme", Proceedings of the 2nd World Conference on Integrated Design and Process Science, Austin, TX

10. Handy, C. B., 1985, "Understanding Organisations," Penguin Books, Harmondsworth, Middlesex, England

11. Barton, R. R., 1996, "Feedback of Manufacturing Experience for DFM Design Rules," Annals of the CIRP, 45, No.1 pp. 115-120.

12. Pahl, G. and Beitz, (1996), "Engineering Design, A Systematic Approach" Second Edition, Springer-Verlag.

13. Valdes-Perez, R.E., (1996) "Computer Science Research on Scientific Discovery", The Knowledge Engineering Review, 11, 1, pp 57-66.

14. Altshuller, G.S., (1984), "Creativity as an Exact Science: The Theory of the Solution of Inventive Problem Solving", Gorden and Breach, London.

15. Barnard, S.C., (1996) "The Theory of Inventive Problem Solving", IEE Colloquium on Process in Design

16. Tsourikov, V.M. (1995), "The Invention Machine $^{\mathrm{TM}}{ }^{\mathrm{N}}$ Invention Machine Corporation.

17. Middleton, R.H., Phillips, G., Rees, D. and Esat, I. (1996) "The Role of Artificial Intelligence in Design, Possibilities and Pitfalls", Proceedings of the 2nd World Conference on Integrated Design and Process Science, Austin, TX.

18. Lenau, T., 1996, "The Missing Element in Design For Manufacture," Annals of the CIRP, 45 , 1, pp. 105-108.

19. Lindermann, $U$. and Irlinger, R. (1996) "Documentation of Product Logic", Proceedings of the 2nd World Conference on Integrated Design and Process Science,Austin, TX.

20. Smith, G.E. (1986), The Dangers of CAD, Mechanical Engineering, 108, No.2, pp 58 -64.

21. Symonds, P.S. and Yu, T.X, (1985) Counterintuitive Behaviour in a Problem of Elastic-Plastic Beam Dynamics, ASME Journal of Applied Mechanics, 52, No.3, pp 517-522.

22. Krause, F., Kimura, F., Kjellberg, T. and Lu, S. (1993) "Product Modelling"; Annals of the CIRP, 42, No. 2, pp 695-706. 